\title{
Adsorption Calorimetric Study of the Organization of Sodium n-Decyl Sulfate at the Graphite/Solution Interface
}

\author{
Z. Király,*,† G. H. Findenegg, ${ }^{\ddagger}$ E. Klumpp, ${ }^{\S}$ H. Schlimper, ${ }^{\S}$ and I. Dékány ${ }^{\dagger}$ \\ Department of Colloid Chemistry, University of Szeged, Aradi Vt. 1, H-6720 Szeged, Hungary, \\ I wan-N.-Stranski-I nstitut für Physikalische und Theoretische Chemie, \\ Technische Universität Berlin, Strasse des 17. J uni 112, D-10623 Berlin, Germany, \\ and Institut für Angewandte Physikalische Chemie, \\ Forschungszentrum J ülich GmbH, D-52425 J ülich, Germany
}

Received November 7, 2000. In Final Form: J anuary 30, 2001

\begin{abstract}
The material and enthal py balances of the adsorption of sodium $n$-decyl sulfate from aqueous solutions ontographitized carbon bl ack were determined between 288 and $318 \mathrm{~K}$ by using an automated flow sorption/ microcal orimeter system. At low concentrations, the surfactant mol ecules form a flat monomol ecular film on the graphite plane, in consequence of surface-directed ordering. A mechanism is proposed in which two adsorbed phases coexist during the formation of this surfactant monolayer. The enthalpy of adsorption in the monolayer region is ca. $-42 \mathrm{~kJ} \mathrm{~mol}^{-1}$, which does not depend appreciably on the temperature or on the surface coverage. At higher concentrations, the ordered monolayer induces surface aggregation to produce half-cylindrical hemimicelles as the critical micelle concentration is approached. The enthal pies of surface aggregation at 288, 298, and $318 \mathrm{~K}$ are $-10,-16$, and $-26 \mathrm{~kJ} \mathrm{~mol}^{-1}$, respectively. As the temperature is increased from 288 to $318 \mathrm{~K}$, the average number of surfactant molecules in the cross section of a half-cylinder drops from ca. 5.4 to 3.4. Calorimetric evidence is provided that cationic and anionic surfactant adsorption on graphite fol low the same mechanism in the low-density and high-density adsorbate regions.
\end{abstract}

\section{Introduction}

It has long been bel ieved that ionicsurfactants adsorbed from aqueous solutions onto the hydrophobic surface of graphite form a vertical monolayer at surface saturation. ${ }^{1-9}$ According to the classical reorientation model, ${ }^{3-7}$ in the first step of adsorption (at concentrations far below the critical micelle concentration, $\mathrm{cmc}$ ) the surfactant molecules adsorb in a horizontal orientation on the graphite surface, and a cl ose-packed monolayer isformed in a headto-tail arrangement, with the hydrocarbon chains lying parallel to one another and to the graphite plane. In the second step of adsorption (at higher concentrations, as the cmc is approached), theadsorbed molecules gradually take up a vertical orientation with the polar head groups directed toward the aqueous phase, thereby facilitating the vertical adsorption of further molecules from the bulk solution until surface saturation occurs at close to the $\mathrm{cmc}$. The idea of this reorientation scheme relies mostly on analysis of the adsorbate densities (or the apparent

* Corresponding author. E-mail: zkiraly@chem.u-szeged.hu.

+ University of Szeged.

‡ Technische Universität Berlin.

$\S$ Forschungszentrum J ülich.

(1) Corrin, M. L.; Lind, E. L.; Roginsky, A.; Harkins, W. D. J . Colloid Sci. 1949, 4, 485.

(2) Sal eeb, F. Z.; Kitchener, J . A. J . Chem. Soc. 1965, 911.

(3) Zettlemoyer, A. C.; Skewis, J. D.; Chessick, J . J . Am. Oil Chem. Soc. 1962, 39, 280.

(4) Zettlemoyer, A. C. J . Coll oid Interface Sci. 1968, 28, 343.

(5) Day, R. E.; Greenwood, F. G.; Parfitt, G. G. In Proceedings of the 4th International Congress on Surface ActiveSubstances; Overbeek, J . Th. G., Ed.; Gordon and Beach: New York, 1967; p 1005.

(6) Greenwood, F. G.; Parfitt, G. D.; Picton, N. H.; Wharton, D. G. In Adsorption from Aqueous Solution; Weber, W. J ., Matijevic, E., E ds.; American Chemical Society: Washington, DC, 1968; p 135.

(7) Hey, M. J .; MacTaggart, J. W.; Rochester, C. H. J . Chem. Soc., Faraday Trans. 1 1984, 80, 699.

(8) Ma, C.; Xia, Y. Colloids Surf. 1992, 66, 215.

(9) Gabrielli, G.; Cantale, F.; Guarini, G. G. T. Colloids Surf. 1996, 119, 163. occupational areas of adsorbed surfactant molecules) calculated along the adsorption isotherm.

Manne et al..$^{10-12}$ and Ducker et al..$^{13-16}$ recently used an atomic force microscope (AFM) to image the adsor bate structure of the ioni c surfactants n-dodecyl, n-tetradecyl, and n-hexadecyltrimethylammonium bromides, ${ }^{10-12}$ ndodecyl sulfate, ${ }^{13-15}$ and n-dodecyldimethylammonium propanesulfonate ${ }^{16}$ at the graphite/aqueous solution interface. These AF M images suggested a two-step adsorption mechanism which markedly differed from that proposed on the basis of the reorientation model. In the first adsorption step, the surfactant molecules selfassemble horizontally on the graphite plane, parallel to each other but in a head-to-head, tail-to-tail arrangement. In the second step, surface hemicylinders are formed in responsetohydrophobicinteractions between theexposed alkyl chains in the ordered monolayer and those of the molecules in the bulk solution.

To date, whereas most AFM studies depict thesituation at full surface coverage, adsorption calorimetry has been applied to study the adsorption process in the subplateau region and also at surface saturation. I n a previous paper, wereported on the material and enthal py balances of the adsorption of $n$-dodecyltrimethylammonium bromide $\left(\mathrm{C}_{12-}\right.$ $T A B$ ) from aqueous solution onto graphite in the temperature range from 288 to $318 \mathrm{~K} .{ }^{17}$ The results of a rigorous thermodynamic analysis were fully consistent with the formation of half-cylindrical aggregates using an ordered monolayer as a template but were not

(10) Manne, S.; Cleveland, J .P.; Gaub, H. E.; Stucky, G. D.; Hansma, P. K. Langmuir 1994, 10, 4409.

(11) Manne, S.; Gaub, H. E. Science 1995, 270, 1480

(12) Manne, S. Prog. Colloid Polym. Sci. 1997, 103, 226.

(13) Wanless, E. J .; Ducker, W. A. J . Phys. Chem. 1996, 100, 3207.

(14) Wanless, E. J .; Ducker, W. A. Langmuir 1997, 13, 1463.

(15) Wanless, E.J .; Davey, T. W.; Ducker, W. A. Langmuir 1997, 13, 4223.

(16) Ducker, W. A.; Grant, L. M. J . Phys. Chem. 1996, 100, 11507.

(17) Király, Z.; Findenegg, G. H. J . Phys. Chem. B 1998, 102, 1203. 
Table 1. Thermodynamic Parameters for the Adsorption and Aggregation of SDeS at the Graphite/Aqueous Solution Interface

\begin{tabular}{cccccccc}
\hline $\mathrm{T}[\mathrm{K}]$ & $\mathrm{cmc}^{\mathrm{b}}[\mathrm{mM}]$ & $\Delta_{\mathrm{mich}} \mathrm{b}^{\mathrm{b}}\left[\mathrm{kJ} \mathrm{mol}{ }^{-1}\right]$ & $\Gamma_{1}{ }^{11} \equiv \Gamma_{1, \max }{ }^{\mathrm{C}}\left[\mu \mathrm{mol} \mathrm{m}^{-2}\right]$ & $\Delta_{21} \mathrm{H}^{\mathrm{c}}\left[\mathrm{mJ} \mathrm{m}{ }^{-2}\right]$ & $\mathrm{n}_{\mathrm{hc}}{ }^{\mathrm{d}}$ & $\Delta_{21} \mathrm{~h}_{1}{ }^{\mathrm{e}}\left[\mathrm{kJ} \mathrm{mol}^{-1}\right]$ & $\Delta_{21} \mathrm{~h}_{1}{ }^{\prime \prime}\left[\mathrm{kJ} \mathrm{mol}^{-1}\right]$ \\
\hline 288.15 & 35.0 & +5.3 & $3.75 \pm 0.21$ & $-74.9 \pm 2.6$ & 5.4 & $-41.2 \pm 4.4$ & $-10.0 \pm 0.8$ \\
298.15 & 33.2 & +1.6 & $3.48 \pm 0.14$ & $-94.9 \pm 4.0$ & 5.0 & $-42.3 \pm 1.8$ & $-16.2 \pm 0.6$ \\
318.25 & 35.0 & -5.8 & $2.37 \pm 0.09$ & $-89.3 \pm 1.7$ & 3.4 & $-42.4 \pm 3.1$ & $-26.1 \pm 0.7$
\end{tabular}

a See text for notations. Heat capacities of aggregation: $\Delta_{\text {mic }} c_{p}=-367 \mathrm{~J} \mathrm{~mol}^{-1} \mathrm{~K}^{-1}$ and $\Delta_{21} \mathrm{C}_{\mathrm{p}}{ }^{11}=-531 \mathrm{~J} \mathrm{~mol}^{-1} \mathrm{~K}^{-1}$. ${ }^{\mathrm{b}} \mathrm{Reference} 19$. c Plateau values with cumulative errors. ${ }^{d}$ Estimated from $n_{h c}=2 \Gamma_{1}{ }^{\prime \prime} / \Gamma_{1}{ }^{l}$ with $\Gamma_{1}{ }^{l}=1.4 \mu \mathrm{mol} \mathrm{m}^{-2}$. e It seems more plausible to take $\Delta_{21} \mathrm{~h}_{1}{ }^{\mathrm{I}}$ $=-42 \pm 3 \mathrm{~kJ} \mathrm{~mol}{ }^{-1}$ in the range from 288 to $313 \mathrm{~K}$. Note: $\Delta_{21} \mathrm{~h}_{1}{ }^{1}$ and $\Delta_{21} \mathrm{~h}_{1}{ }^{11}$ are not affected by the cumulative errors in $\Gamma_{1}$ and $\Delta_{21} \mathrm{H}$.

congruent with the earlier reorientation model. Although surface aggregation was found to be some $15 \mathrm{~kJ} \mathrm{~mol} \mathrm{~m}^{-1}$ more exothermic than micelle formation in the bulk solution, thepronounced temperature dependences of the two processes were remarkably similar. The number of surfactant molecules in a sheet perpendicular tothemajor axis of a half-cylinder at $298 \mathrm{~K}$ was ca. 5, with a temperature dependence similar in magnitude to that of the aggregation number of bulk micelles.

Following our previous calorimetric studies on the adsorption of cationi $c^{17}$ and nonionic surfactants ${ }^{18}$ at the graphite/water interface, in this paper we report on the adsorption isotherms and the calorimetric enthalpies of adsorption of an anionicsurfactant, sodiumn-decyl sulfate (SDeS), on graphite at three different temperatures: 288.15, 298.15, and $318.15 \mathrm{~K}$. A thermometric titration study on the micell ization of SDeS in aqueous sol ution in the same range of temperature was reported recently. ${ }^{19}$ Although sodium n-dodecyl sulfate (SDS) is at present the most frequently investigated anionicsurfactant in the adsorption literature, SDeS seemed to be a better candidate for the current flow sorption microcalorimetric study. This is because SDeS has a higher $\mathrm{cmc}$ and is less strongly adsorbed on graphite than SDS, therefore allowing a better resolution of the adsorption both at low and at higher concentrations. It will be shown that our results are fully consistent with current views on surface aggregation at the solid/solution interface and that the mechanisms of cationic and anionic surfactant adsorption on graphite are very similar.

\section{Experimental Section}

Materials. SDeS (99\% pure) was obtained from Fluka and was used as received. Sol utions weremade up with distilled water passed through a Milli-Q filtration system. Vulcan 3G (V3G), a carbon black of Cabot Corp., graphitized by Sigri Elektrographite $\mathrm{GmbH}$, M eitingen, was taken from the same lot as in previous studies. ${ }^{17,18}$ The graphite pearls had a specific surface area of 68 $\mathrm{m}^{2} \mathrm{~g}^{-1}$ to $\mathrm{N}_{2}$ at $77 \mathrm{~K}$. The mean size of the primary particles was determined by transmission electron microscopy to beca. $40 \mathrm{~nm}$.

Methods. The automated equipment and the procedure applied during this study were described in detail in recent papers. ${ }^{17,20}$ Measurements of the adsorption isotherm ( $\Gamma_{1}$ Vs $\left.C_{1}\right)$ in parallel with the calorimetric enthalpy isotherm of displace ment $\left(\Delta_{21} \mathrm{H}_{1}\right.$ VS $\left.\mathrm{C}_{1}\right)$ were made at $288.15,298.15$, and $318.15 \pm$ $2 \times 10^{-4} \mathrm{~K}$ on the principle of flow frontal analysis solid/liquid chromatography. The term "displacement" refers here to the adsorption process during which the solvent (component 2 ) is stepwise displaced by the solute (component 1 ) at the solid/ soluti on interface. Typically, $0.2 \mathrm{~g}$ of V $3 \mathrm{G}$ was weighed in a small chromatographic column and placed insidethe measuring block of a Thermal Activity M onitor 2277 microcalorimeter (ThermoMetrics, Lund, Sweden). A high-performanceliquid chromatography (HPLC) system (from Merck, Darmstadt, Germany at 288.15 and 298.15 K and from Knauer, Berlin, Germany at 318.15

(18) Király, Z.; Findenegg, G. H. Langmuir 2000, 16, 8842

(19) Király, Z.; Dékány, I. J . Colloid Interface Sci., submitted for publication

(20) Király, Z. In Thermal Behavior of Dispersed Systems; Garti, N., Ed.; Dekker: New York, 2000; p 335.
K) was connected tothecal orimeter. TheHPL C system was used to control the liquid flow (ca. $6 \mathrm{~cm}^{3} \mathrm{~h}^{-1}$ ), to change the solutions entering the col umn (in 10-12 consecutive concentration steps, starting from pure water up to the $\mathrm{cmc}$ ), and to monitor the concentration waves (in terms of refractive index variation) passing through the column. Ideal chromatographic behavior assumes a permanent plug flow, which implies that the breakthrough curve is a sharp step function. For real processes, the breakthrough curves are broadened on the time scale (because of back-mixing, channeling, or other complexities) and the enthalpy of mixing at the interface between the replacing and replaced solutions may contribute to the total heat measured. However, for dilute solutions and if small concentration steps are applied (as for the present experiments), the enthalpy of mixing in this boundary region can safely be neglected. ${ }^{20,21} \mathrm{~F}$ or each concentration step $\Delta c_{1}$, theretention timet $t_{R}$ was determined from the concentration profile. 22 The amount adsorbed during a step $\Delta \mathrm{c}_{1}$ was calculated as $\Delta \Gamma_{1}=\mathrm{Qt}_{\mathrm{CR}} \Delta \mathrm{c}_{1} / \mathrm{ma}_{\mathrm{s}}$, where $\mathrm{Q}$ is the liquid flow rate, $t_{C R}$ is the retention time corrected for the deadtime, and $m$ and $a_{s}$ are the mass and the specific surface area, respectively, of the solid. The heat $\Delta_{\mathrm{d}} \mathrm{H}$ associated with this adsorption step was detected by the calorimeter so that the (pseudo) differential enthalpy of displacement was directly measured for each step: $\Delta_{21} h_{1}=\Delta_{d} H / \Delta \Gamma_{1}$. Alternatively, summation of themeasured adsorption increments and the measured heats over the wholeconcentration range provided theadsorption isotherm $\Gamma_{1}$ versus $C_{1}$ and the cumulative enthal py isotherm of displacement $\Delta_{21} \mathrm{H}_{1}$ versus $\mathrm{C}_{1}$. Whereas adsorption-desorption cycles indicated nonreversibleadsorption steps at high dilutions $\left(c_{1}<1 \mathrm{mmol}^{-3}\right)$, fairly reversible adsorption steps were experienced at higher concentrations $\left(\mathrm{c}_{1}>1 \mathrm{mmol} \mathrm{dm}^{-3}\right)$. Similar observations have been made for closely related systems. ${ }^{18,23}$

Theaccuracy of theadsorption measurements varied between 2 and $8 \%$, depending on the concentration step. The precision was slightly better for the calorimetric experiments. The cumulative errors are given in Table 1 (see Discussion). The lower accuracy of the present results compared to those experienced for $\mathrm{C}_{12} \mathrm{TAB}^{17}$ must be noted and commented on. SDeS is susceptible to hydrolysis in aqueous media, which might occur upon storage of the solutions in the time scale of the experiments. ${ }^{19}$ Hence, our results may be slightly influenced by the appearance of somen-decanol, a product of thenatural hydrolysis of SDeS. Wemay refer toan AFM study, however, which indicated that the presence of n-dodecanol originating from the selfhydrolysis of SDS had only a minor effect, if any, on the surface aggregation of SDS at the graphite/solution interface. ${ }^{15} \mathrm{~F}$ urther addition of $n$-dodecanol did influence the structure of the interfacial SDS aggregates.

\section{Results}

The adsorption of SDeS from aqueous solutions onto graphite exhibited a normal temperature dependence $\left(\Gamma_{1}\right.$ decreased with increasing $T$ ), as depicted in theadsorption isotherms in Figure 1. For each temperature, theisotherm was of the double-plateau (LS) type, which leveled off at the cmc. The two plateaus tended to merge into a single plateau as the temperature was further increased. Our

(21) Woodbury, G. W., I r.; Noll, L. A. Colloids Surf. 1987, 28, 233. (22) Koch, C. S.; Köster, F.; Findenegg, G. H. J . Chromatogr. 1987, 406,257

(23) Findenegg, G. H.; Pasucha, B.; Strunk, H. Colloids Surf. 1989, 


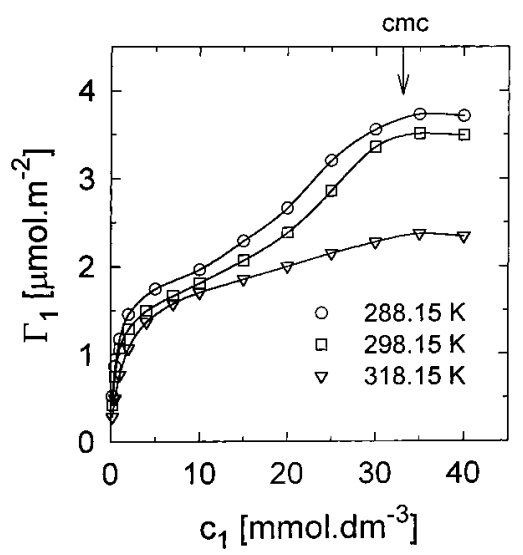

Figure 1. Adsorption isotherms for thesystem SDeS(1)-water(2)Nulcan 3G graphitized carbon black at 288.15, 298.15, and $318.15 \mathrm{~K}$. The arrow indicates the $\mathrm{cmc}$ region (34 $\pm 1 \mathrm{mM}$ in the present temperature range (ref 19)).

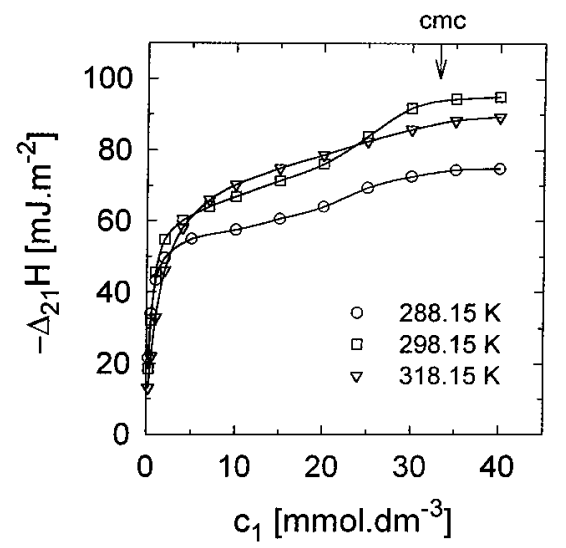

Figure 2. Integral enthal py isotherms of displacement for the system SDeS(1)-water (2)Nulcan 3G graphitized carbon black at $288.15,298.15$, and $318.15 \mathrm{~K}$. The arrow indicates the $\mathrm{cmc}$ region (34 $\pm 1 \mathrm{mM}$ in the present temperature range (ref 19)).

results can be directly compared with the adsorption isotherm of Gabrielli et al., who reported a plateau value of ca. $\Gamma_{1 \text { max }}=5 \mu \mathrm{mol} \mathrm{m}-2$ for SDeS on Graphon at 294.6 $\mathrm{K} .{ }^{9}$ This value is significantly higher than the present values of 3.48 and $3.74 \mu \mathrm{mol} \mathrm{m} \mathrm{m}^{-2}$ at the neighboring temperatures of 298.15 and $288.15 \mathrm{~K}$, respectively, and significantly higher than the plateau for SDS, which is $3.8 \pm 0.2 \mu \mathrm{mol} \mathrm{m}^{-2}$ at $298.15 \mathrm{~K}^{3-8}$ and $3.3 \mu \mathrm{mol} \mathrm{m} \mathrm{m}^{-2}$ at $303.15 \mathrm{~K}^{1}{ }^{1}$ I $\mathrm{n}$ favor of the present results, we refer to the general trend observed on graphite: at a fixed temperature and within a surfactant homolog series, the maximum adsorption increases with increasing al kyl chain length. As concerns the cationics, we obtained $3.2 \mu \mathrm{mol} \mathrm{m}^{-2}$ for $\mathrm{C}_{12} \mathrm{TAB}$ at $298.15 \mathrm{~K},{ }^{17}$ which may be compared with the $4.2 \mu \mathrm{mol} \mathrm{m} \mathrm{m}^{-2}$ for $\mathrm{C}_{16} \mathrm{TAB}$ at the same temperature. ${ }^{2} \mathrm{~A}$ similar trend was observed for the nonionic n-alkyl polyoxyethylene glycol monoethers ${ }^{23,24}$ and alkylsulfinylethanols $\mathrm{s}^{25}$ adsorbed on graphite.

Thecal orimetricenthal pies of displacement are depicted in Figure2. At each temperature, theshapeof theenthal py isotherm is qualitatively similar to that of the correspondingadsorption isotherm. In thewholeconcentration range studied, the adsorption is exothermic. It appears, however, that the extent of this exothermic character is dependent on the temperature. The maximum amounts

(24) Corkill, J . M.; Goodman, J . F.; Tate, J . R. Trans. Faraday Soc. 1966, 62, 979.

(25) Corkill, J . M.; Goodman, J . F.; Tate, J . R. Trans. Faraday Soc. 1967, 63, 2264.

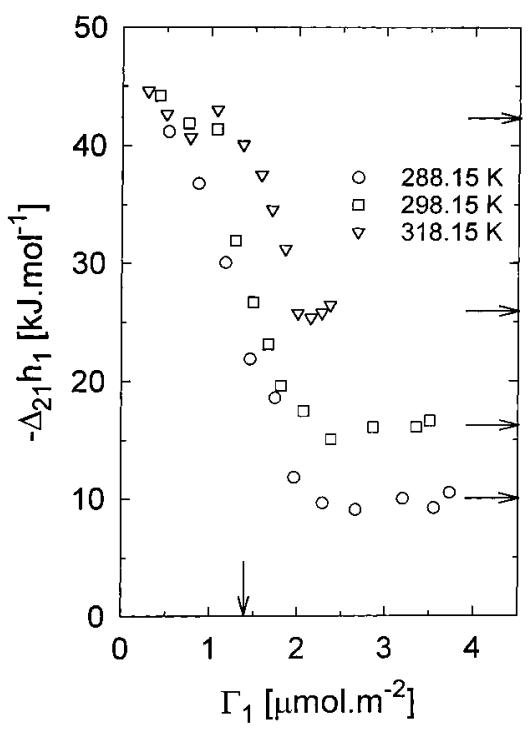

Figure 3. Differential molar enthal pies of displacement for the system SDeS(1)-water(2)Nulcan 3G graphitized carbon black at 288.15, 298.15, and 318.15K as functions of thesurface coverage.

adsorbed and the cumulative enthalpies at the $\mathrm{cmc}$ are listed in Table 1.

\section{Discussion}

Interestingly, the enthalpy curves cross each other (Figure2), whereas theadsorption isotherms donot exhibit this kind of (apparent) anomaly (Figure 1). It should be noted, however, that the adsorption isotherms and the cumulative enthalpy isotherms of displacement as functions of the equilibrium concentration $\left(\Delta_{21} \mathrm{~h}\right.$ vs $C_{1}$ and $\Gamma_{1}$ VS $C_{1}$ ) do not betray much concerning the mechanism of adsorption. Toget a better insight, the (pseudo) differential molar enthal pies of displacement $\Delta_{21} h_{1}$ are plotted against the surface concentration $\Gamma_{1}$ in Figure 3; the abovementioned apparent anomaly is absent in this representation. $\Delta_{21} \mathrm{~h}_{1}$ is defined as the difference between the partial molar enthal pies of the solute (component 1 ) and the solvent (component 2) in the adsorbed layer (superscript s) and in the bulk solution (superscript I):26

$$
\Delta_{21} h_{1}=\left[\frac{\partial\left(\Delta_{21} \mathrm{H}\right)}{\partial \Gamma_{1}^{s}}\right]_{T, p, a_{s}}=\left(h_{1}^{s}-h_{1}^{1}\right)-r\left(h_{2}^{s}-h_{2}^{1}\right)
$$

where $\Delta_{21} \mathrm{H}$ is the integral (or cumulative) enthalpy of displacement of 2 by 1 and $r$ represents the number of moles of solvent displaced by one mole of solute at the solid/solution interface of specific surface area $a_{\text {s. }}$ It appears from Figure 3 that, at each temperature, the adsorption of SDeS from aqueous solutions onto graphite proceeds in two distinct steps. A strongly exothermic adsorption step at low adsorbate densities (region I) is followed by a less exothermic adsorption step at high adsor bate densities (region II). Theenthal py of adsorption in region I does not changemuch with thesurface coverage or with variation in temperature. The enthal py of adsorption in region II is little affected by the surface coverage but is strongly dependent on the temperature. There is a transition region between the two modes of adsorption. The marked difference between the adsorption mechanisms in the two regi ons has recently been establ ished at

(26) Király, Z.; Dékány, I .; Klumpp, E .; L ewandowski, H.; Narres, H. D.; Schwuger, M. J . Langmuir 1996, 12, 423. 
a molecular level by using AFM ${ }^{10-16}$ and at a thermodynamic level by using adsorption microcalorimetry. ${ }^{17,18}$ Accordingly, wemay postulatetheformation of an ordered monolayer in region I, followed by the formation of hemicylindrical surface micel les in region II. The further discussion is based on this postulation. The earlier reorientation model, ${ }^{3-8}$ which has been shown not to be applicablefor theadsorption of surfactants at thegraphite/ water interface, ${ }^{10-18}$ is not considered in the present work.

Adsorption Process in Region I. The adsorption in the low-density adsorbate region is strongly exothermic (Figure 3) and has been found to be nonreversible; only a fraction of the firmly bound SDeS monolayer can be removed in desorption steps, even on washing with pure water. The major driving forces of this high-affinity adsorption process arethestrong hydrophobic interaction between thesurfactant tails and thegraphitesurfaceand, in part, the energetically favored epitaxial ordering due to the nearly perfect matching of the alkyl skeletons in a zigzag conformation with the carbon hexagons of the graphite basal planes. 27,28 The differential molar heat of adsorption $-\Delta_{21} \mathrm{~h}_{1}{ }^{1}$ of SDeS on graphite is apparently independent of (or slightly decreases with) the surface coverage (and temperature), amounting to ca. $42 \mathrm{~kJ} \mathrm{~mol}^{-1}$ (Table 1). For comparison, $-\Delta_{21} \mathrm{~h}_{1}{ }^{\prime}=61 \mathrm{~kJ} \mathrm{~mol}{ }^{-1}$ has been reported for $\mathrm{C}_{12} \mathrm{TAB} .{ }^{17}$ This difference in bond strength signifies the importance of the length of the alkyl chains in contact with the hydrophobic surface. Although the enthal pic interactions between thesurfactant headgroups and the graphite planes are probably small, these interactions must be different for anionic and cationic surfactants. Because the graphite surface possesses a moderate electrical conductivity, it seems plausible that the anionic sul fate headgroup induces repulsive interactions with the $\pi$-electrons of thehighly condensed basal planes, whereas the cationic ammonium head can to some extent be attracted by them. 10,11,17 The apparent temperature independence of $\Delta_{21} \mathrm{~h}_{1}{ }^{\prime}$ (within the present experimental uncertainty) is not cl early understood. It may be a result of a compensation effect: the expected positive temperature coefficient of the enthalpy change (heat capacity) due to direct contact between the surfactant molecules and the graphite surface may be accompanied and counterbalanced by a negative heat capacity change due to (partial) dehydration of the surfactant molecules as they become adsorbed. As far as the surface coverage at a fixed temperature is concerned, experimental data for $\Gamma_{1}$ values smaller than those displayed in Figure 3 were not obtained because of the very high affinity of SDeS for thesubstrateeven from very dilutesolutions. Theenthal py of adsorption in this region should therefore be regarded as an integral molar quantity rather than a differential molar quantity. Nevertheless, the calorimetric data for the adsorption of $C_{10} T A B, C_{8} T A B$, and $C_{6} T A B$ surfactants, ${ }^{29}$ which are less strongly bound to the graphite surface and for which more experimental points were ther eforeattainable at low surface coverages, support the approximate constancy of $\Delta_{21} h_{1}{ }^{l}$ in adsorption region I. This observation implies that theadsorption layer behaves nearly ideally in themonolayer regime. Thereis noa priori reason to believe that a mixture of surfactant and water molecules would behave ideally unless phase separation occurs. If so, the ideal behavior can be explained in terms of the existence of a two-phase equilibrium within the adsorption layer, wherein pure water and essentially pure surfactant films coexist (theterm "essentially pure" allows

(27) Groszek, A. J . Proc. R. Soc. London, Ser. A 1970, 134, 473.

(28) Rabe, P. J .; Buchholz, S. Science 1991, 253, 424.

(29) Király, Z.; Findenegg, G. H. To be published. thepicture of headgroup hydration). Theadsorbed phases are in equilibrium with each other and with the bulk solution. The compositions of theadsorbed phases remain unchanged as the adsor ption proceeds; only their relative ratio changes in favor of the surfactant phase. Such a model was first proposed by Findenegg et al. for the adsorption of Iong-chain alcohols from nonaqueous solvents onto graphite. ${ }^{30}$ We further propose that at a very early stage of the adsorption process isolated SDeS molecules are adsorbed in registry with the graphite surface along one of the three graphite symmetry axes. I nitially, these adsorbate molecules form tiny islands on thegraphitesurface, serving as nuclei for two-dimensional growth (quasi-crystallization) at the expense of surfacebound water. Within a single two-dimensional domain, the surfactant molecules are oriented along the same graphitesymmetry axis and self-assembleparallel to each other and in a head-to-head, tail-to-tail arrangement so that the orientation of the rows of laterally bound surfactant molecules is perpendicular to the symmetry axis. This adsorption mechanism is consistent with AFM images at a later stage of the adsorption process, because only three domain orientations (at $120^{\circ}$ to each other, $0.25-1 \mu \mathrm{m}^{2}$ in size) were observed across the surface and the repeat spacing in a domain was a little over twice the length of a fully extended surfactant molecule.10-16

The Transition Region. A significant change in the mode of adsorption occurs where $-\Delta_{21} h_{1}$ begins to fall with increasing $\Gamma_{1}$ (Figure3). Thetwo modes of adsorption overlap so that a transition zone appears. Prior to completion of the flat monolayer in adsorption region I, the adsorbed surfactant molecules are sufficiently preconcentrated by thegraphitesurfacetoinduceaggregation on top of the monolayer patches. At this critical surface aggregation concentration (csac), half-cylindrical hemimicelles begin to form, with the underlying ordered monolayer as a template. This picture implies that the formation of surface hemicylinders is accompanied by further horizontal adsorption until the maximum monolayer coverage $\left(\Gamma_{1}{ }^{l}\right)$ is reached. Surface aggregation is less exothermicthan adsorption in direct contact with thesolid surface $\left(-\Delta_{21} h_{1}{ }^{\prime \prime}<-\Delta_{21} h_{1}^{\prime}\right)$, thereby resulting in a net decrease in $-\Delta_{21} h_{1}$ with increasing $\Gamma_{1}$ (Figure 3). $\Delta_{21} h_{1}$ represents a mean enthalpy in the transition zone; the enthalpy of adsorption is weighted along the $\Gamma_{1}$ axis in proportion to the contributions of the two modes of adsorption; the process gradually changes from purely horizontal (region I) to purely aggregative (region II) adsorption. Although a normal temperature effect would suggest that $\Gamma_{1}{ }^{1}$ is higher at lower temperature, a decrease in temperature induces surface aggregation at lower $\Gamma_{1}{ }^{1}$. By way of analogy, it was found for the formation of cylindrical micelles that the critical rod concentration decreases with decreasing temperature for a series of cationic surfactants. ${ }^{31}$ It is difficult to define the position of the (hypothetical) completion of themonolayer because thetransition zoneissmeared out over a rangeof adsorbate densities. The transition region becomes less diffuse as the temperature is decreased. The nominal value of $\Gamma_{1}{ }^{1}$ lies somewhere in the interval of $1.2-1.6 \mu \mathrm{mol} \mathrm{m} \mathrm{m}^{-2}$ along the descending section of the $-\Delta_{21} h_{1}$ versus $\Gamma_{1}$ curve, and it is probably dependent on the temperature. For simplicity, we take an approximate value of $\Gamma_{1}{ }^{\prime}=1.4 \mu \mathrm{mol} \mathrm{m}{ }^{-2}$ to estimate the "real" surface coverage with respect to a

(30) Findenegg, G. H.; Koch, C.; Liphard, M. In Adsorption from Solution; Ottewill, R. H., Rochester, C. H., Smith, A. L., Eds.; Academic: London, 1983; p 87.

(31) Nusselder, J .J . H.; Engberts, J . B. F. N.J . Colloid I nterfaceSci 1992, 148, 353. 
close-packed flat monolayer. Hey et al. applied the geometric model of Groszek ${ }^{27}$ for thehorizontal adsorption of SDS on graphite. ${ }^{7}$ Adopting these geometric considerations for SDeS, we obtain that only ca. $66 \%$ of the total surface area of graphite is occupied by SDes molecules, the rest being covered by water molecules, which may also participatein headgroup hydration. For comparison, a maximum surface coverage of $73 \%$ has been reported for $\mathrm{C}_{12} \mathrm{TAB}$ on V3G. ${ }^{17}$ The monomolecular adsorption capacities estimated for SDeS and $C_{12} T A B$ fromadsorption and cal orimetric data can be compared with AFM images which indicated periodicities (aggregate diameter plus interaggregatedistance) between 2 and 3 times thelength of the surfactant molecules in the all-trans conformation. 12,13 This observation allows a water content up to $33 \%$ in a completed surfactant monolayer. The major difference between the graphite sample V3G used in the present work and in our previous studies ${ }^{17,18}$ and the graphite sample, a cleavage of pyrolytic graphite monochromator used in AFM experiments, ${ }^{10-16}$ is that V3G consists of colloidal particles, whereas the cleaved graphite is of macroscopic size. Hence, the patches of uniform area are smaller for V3G, and a higher proportion of the area is cl ose to pol ar edges al ong which thegraphitecrystallites merge. This can account for a higher water content in a surfactant monolayer on V3G.

Adsorption Process in Region II. The number of surfactant molecules in a sheet perpendicular tothemajor axis of a half-cylinder can be calculated as $n_{h c}=2 \Gamma_{1}{ }^{11} /$ $\Gamma_{1}{ }^{1} .^{17}$ The maximum amount adsorbed $\left(\Gamma_{1}{ }^{11} \equiv \Gamma_{1 \text {,max }}\right.$, the plateau value on the isotherm) is given for each temperature in Table 1. Taking $\Gamma_{1}{ }^{1}=1.4 \mu \mathrm{mol} \mathrm{m}^{-2}$ for SDeS, the calculation yields $n_{\mathrm{hc}}$ values ranging from 5.4 to 3.4 as the temperature is increased from 288.15 to $318.15 \mathrm{~K}$ (Table 1). In view of the data availablefor cl osely related systems, the nominal values and the negative temperature dependence of $n_{h c}$ for SDeS hemicylinders on graphite seem to be plausible. For example, $n_{h c}$ values between 5.1 and 4.5 were obtained from cal orimetric investigations of the adsorption of $\mathrm{C}_{12} \mathrm{TAB}$ on graphite, in the same range of temperature as in the present work. ${ }^{17}$ In another calorimetric study, we obtained 4.0 and 5.1 for two nonionic surfactants adsorbed on graphite at $298.15 \mathrm{~K} .{ }^{18} \mathrm{~F}$ urther, an AFM study on the organization of SDS on graphite at room temperature suggested $n_{h c}=5$ cl ose to the $\mathrm{cmc}^{13}{ }^{13} \mathrm{n}$ all cases, low values for $n_{h c}$ were obtained, indicating that surfactant molecules in the aggregativeadsorption region are less strongly held in the adsorption layer (they are more dynamic) than surfactant mol ecules in direct contact with the graphite surface. The difference in the strength of adsorption in regions I and II may be inferred from a comparison of the magnitudes of the corresponding adsorption enthalpies, $\Delta_{21} h_{1}{ }^{\prime}$ and $\Delta_{21} h_{1}{ }^{\prime \prime}$ (Table 1), and from the reversible character of the adsorption process in region II as compared with the nonreversible nature of the adsorption process in region I. Zettlemoyer detected theadsorption of sodium cations and dodecyl sulfateanions separately by using a radiotracer technique; 4 no sodium ions were adsorbed on the graphite surface unless the organic ions were previously adsorbed. The counterion was found to adsorb in the diffuse double layer, but the amount taken up was less than that of the surfactant anion below the $\mathrm{cmc}$ and greater than it above the $\mathrm{cmc}$, suggesting that at surfacesaturation theadsorbed dodecyl sulfate took up sodium ions preferentially, leaving the bulk micelles deficient. The present adsorption/calorimetric technique cannot be used to resolve the stoichiometry of the adsorption of sodium ions and decyl sulfate ions al ong the adsorption isotherm.

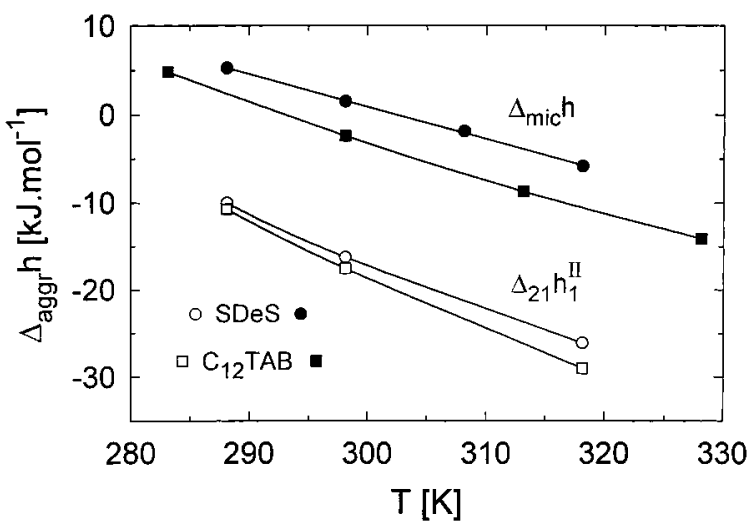

Figure 4. Molar enthal pies of aggregation ( $\left.\Delta_{\text {aggr }} h\right)$ of SDeS (this work) and $\mathrm{C}_{12} \mathrm{TAB}$ (ref 17) plotted against temperature: $\Delta_{\text {mich, }} \mathrm{h}$ in aqueous solution; $\Delta_{21} \mathrm{~h}_{1}{ }^{11}$, at the graphite/water interface.

Figure 3 suggests that the enthalpy of hemicylinder formation, $-\Delta_{21} h_{1}{ }^{\prime \prime}$, is not (or only slightly) dependent on the surface coverage but is strongly dependent on the temperature. The enthal pies of aggregation $\left(\Delta_{\text {aggr }} h\right)$ of SDeS in aqueous bulk solution $\left(\Delta_{\text {mic }} h\right)$ and at thegraphite/ water interface $\left(\Delta_{21} h_{1}{ }^{\prime \prime}\right)$ are compared at different temperatures in Figure 4. Although the formation of surface hemicylinders is more exothermic than the formation of globular micelles in free solution, the temperature dependences of the enthalpy changes are rather similar. This trend might be envisaged from the sphere-to-rod transition of some cationic surfactants (in the absence of electrolytes) with enthal py changes in the range from -2 to $0 \mathrm{~kJ} \mathrm{~mol} \mathrm{mo}^{-1}{ }^{31}$ and the sphere-to-rod transition of SDS in aqueous solution (in the presence of el ectrolyte), which is likewise slightly exothermic with a negligible change in the heat capacity. ${ }^{32,33}$ The unfavorable interactions between alkyl chains and water diminish greatly upon chain-chain association, either in free solution or at the graphite/solution interface. The major thermodynamic driving force is similar in the two cases: a change in hydration of the monomer upon aggregation. It is the monomer rather than the micellar state which is influenced by the temperature change also. Headgroup hydration is less sensitive to temperature variation than the hydrophobic hydration of the tails. ${ }^{33}$ In free solution, it is the repulsiveinteractions between the headgroups which dictate the molecular packing arrangement. At the graphite/solution interface, however, the molecular packing arrangement is largely determined by the substrate, which facilitates interfacial ordering and imposes geometric constraints on the aggregate shape. For a further comparison, the enthal pies of micellization of $\mathrm{C}_{12} \mathrm{TAB}$ in aqueous bulk solution at the $\mathrm{Cmc}^{34}$ and the enthal pies of aggregation of $C_{12} T A B$ at the graphite/water interface ${ }^{17}$ are displayed in Figure $4 . \Delta_{\text {mich }}$ for SDeS is shifted in the endothermic direction as compared with $\mathrm{C}_{12} \mathrm{TAB}$. Although the enthal pies of surface aggregation for SDeS are less exothermicthan thosefor $C_{12} T A B$, thedifferencesin $\Delta_{21} h_{1}{ }^{11}$ areless significant and areclosetothe experimental error in the determination of $\Delta_{21} h_{1}$. In bulk solution, the heat capacities $\left(\Delta_{\text {mic }} C_{\mathrm{p}}\right)$ at the $\mathrm{cmc}$ are $-367 \mathrm{~J} \mathrm{~mol}^{-1} \mathrm{~K}^{-1}$ for SDeS ${ }^{19}$ and $-422 \mathrm{~J} \mathrm{~mol}^{-1} \mathrm{~K}^{-1}$ for $\mathrm{C}_{12} \mathrm{TAB}^{34}$ The heat capacities of surface aggregation $\left(\Delta_{21} C_{p}{ }^{\prime \prime}\right)$ are -530 and $-605 \mathrm{~J} \mathrm{~mol}^{-1} \mathrm{~K}^{-1}$ for SDeS (this work) and $\mathrm{C}_{12} \mathrm{TAB},{ }^{17}$

(32) Missel, P.J .; Mazer, N. A.; Benedek, G. B.; Young, C. Y .; Carey, M. C. J . Phys. Chem. 1980, 84, 1044.

(33) Mazer, N. A.; Olofsson, G. J . Phys. Chem. 1982, 86, 4584

(34) Bashford, M. T.; Wooley, E. M. J . Phys. Chem. 1985, 89, 3173. 
respectively. Both in thebulk solution and at thegraphite/ water interface, $\Delta_{\text {aggr }} \mathrm{C}_{\mathrm{p}}\left(\mathrm{C}_{12} \mathrm{TAB}\right)<\Delta_{\text {aggr }} \mathrm{C}_{\mathrm{p}}(\mathrm{SDeS})$, which is mostly ascribed to the different chain lengths of the two surfactants; the headgroup effect on $\Delta_{\mathrm{aggr}} \mathrm{C}_{\mathrm{p}}$ is of secondary importance. ${ }^{19,31} \mathrm{~F}$ or a given surfactant, $-\Delta_{21} C_{p}{ }^{\prime \prime}>-\Delta_{\text {mic }} C_{p}$, which implies that interfacial aggregation is more sensitivetotemperaturevariation than aggregation in the bulk solution. This is supported by the strong temperature dependence of $n_{h c}$. I ndeed, for SDeS, surface aggregation may disappear entirely at temperatures not too far from the highest temperature investigated in this work.

Calorimetric evidence of the similarity between the mechanisms of cationic and anionic surfactant adsorption on oppositely charged crystall ine oxide surfaces has been given by Zajac et al. ${ }^{35}$ The present work, together with our previous study, ${ }^{17}$ provides calorimetric evidence concerning the similarity between the mechanisms of cationic and anionic surfactant adsorption on the hydrophobic surface of graphite.

\section{Conclusions}

The adsorption of SDeS from aqueous solution onto graphite follows a two-step mechanism as a function of the surfactant concentration. In the first step, at low concentrations, a flat, ordered monolayer is formed. This process is strongly exothermicand apparently independent of (or only slightly dependent on) the temperature and the surface coverage. We propose a mechanism in which two adsorbed phases (water-rich and surfactant-rich domains) coexist during monolayer formation. In the second step, as the solution concentration is increased

(35) Zajac, J .; Lindheimer, M.; Partyka, S. Prog. Colloid Polym. Sci. 1995, 98, 303. toward the cmc, loosely packed surface hemicylinders are formed, this being facilitated by the underlying monolayer. The second adsorption step is less exothermic than the first, apparently independent of (or only slightly dependent on) the surface coverage, but strongly dependent on the temperature. Our results indicatethat surfaceaggregation begins close to but earlier than the completion of this monolayer. The proposed mechanism can beconfirmed or confuted by AFM investigations, in which attention is focused on the low-density adsorbate region. The aggregation behaviors of SDeS in aqueous solution and at the graphite/solution interface share many common properties originating from intermolecular hydrophobic interactions. The quantitative differences in terms of enthalpies, heat capacities, and molecular packing are mostly attributed to thespecific properties of the graphite substrate. Calorimetric evidence is furnished that the adsorption and aggregation of cationic and anionic surfactants follow the same adsorption mechanism on the surface of graphite. Finally, it is envisioned that a combination of adsorption cal orimetry (thermodynamic level) with AFM (molecular level), applied to the same system, is a most promising way to investigateadsorption phenomena at solid/solution interfaces.

Acknowledgment. This work was supported by a fellowship from the Alexander von Humbol dt F oundation (Z.K.), by the Hungarian-German Intergovernmental Science and Technology Cooperation Program (OMFB/ BMBF), and by grants from the Hungarian Science Foundation (OTKA T025002) and from the Deutsche Forschungsgemeinschaft (SFB 448).

LA001552Y 